\title{
The Trend of Tranexamic Use in Upper Gastrointestinal Bleeding Ulcers
}

\author{
Stefan Redeen
}

\begin{abstract}
Background: Bleeding ulcer is a common condition, especially among the elderly population. Tranexamic acid (TXA) has been successfully used for many bleeding conditions. Its use in patients with bleeding ulcer is inclusive yet. The aim of this study was to provide an overview of the prescription of TXA.
\end{abstract}

Methods: This retrospective cohort study was performed as a review of medical records at the Surgery Department, University Hospital in Linkoping. Patients with complete esophagogastroduodenoscopy and ulcer disease were included and divided on the basis of treatment with TXA or not. Differences between the groups were statistically analyzed.

Results: The main part of the prescription of TXA, $65 \%$, occurred during 2010 and 2011, and 35\% between 2012 and $2013(\mathrm{P}<0.05)$. In the group treated with TXA, $84 \%$ needed blood transfusion, compared to $64 \%$ in the control group $(\mathrm{P}=0.039)$. Of the patients treated with TXA, $18 \%$ were re-bleeding compared to $14 \%$ of the controls (P $=0.594)$. Median value for days at hospital was 5 in the tranexamic group and 3 in the control group $(\mathrm{P}=0.005)$.

Conclusion: The prescription of TXA has declined between 2010 and 2013. TXA was more often prescribed to patients with more severe gastrointestinal (GI) bleeding ulcer disease. Further investigation is needed to conclude the significance of tranexamic acid in patients with GI bleeding ulcer disease.

Keywords: Bleeding ulcer; Esophagogastroduodenoscopy; Hematemesis; H. pylori; Melena; Tranexamic acid

\section{Introduction}

Upper gastrointestinal (GI) bleeding is a common and po-

Manuscript submitted April 10, 2017, accepted May 12, 2017

Department of Surgery and Department of Clinical and Experimental Medicine, Linkoping University, Linkoping, Sweden.

Email: Stefan.redeen@regionostergotland.se

doi: https://doi.org/10.14740/gr836w tentially fatal condition [1]. Peptic ulcer from the stomach or duodenum is the most common cause of bleeding disease in the upper GI tract leading to hospitalization for approximately 35 per 100,000 inhabitants in Sweden in 2005 [2]. Hospitalization for bleeding ulcer declined between 1987 and 2005, while mortality from ulcer disease increased from $5 \%$ to $6 \%$. This is probably a result of the older patient group, since the median age for ulcer disease is 76 years, maybe due to comorbidity [1]. Approximately $80 \%$ of ulcer patients spontaneously stop bleeding [3]. Duodenal ulcer is more common among males [4], although the incidence is increasing among elder women [4].

The treatment of choice for patients suffering from bleeding ulcers is to stop the bleeding and prevent further bleeding. Endoscopic treatment with adrenaline injection and other methods is the state of art recommendation [5]. In addition, medical treatment comprises proton pump inhibitors (PPIs) intravenous or oral [6] and therapies eradicating H. pylori, the last one to prevent re-ulcer and possible re-bleeding events [7].

In the bleeding ulcers, after treatments, when coagulation has started, the fibrin clots are eventually degraded through fibrinolysis, which is important to maintain hemostasis. Medical treatment of peptic ulcer sometimes implicates tranexamic acid (TXA), which is a synthetic agent with antifibrinolytic effects due to its inhibiting action on plasminogen by inhibiting its lysine binding sites [8]. TXA is consequently an antifibrinolytic medication and has been successfully used in different clinical trials [9-12].

The randomized CRASH-2 trial included in total 20,211 trauma patients from 40 countries, and they concluded that TXA decreased the bleeding mortality from $5.7 \%$ in the placebo group, to $4.9 \%$ in the TXA group [9]. Furthermore, TXA medication seems to have a positive impact on patients going through radical retro pubic prostatectomy [10], as well as it reduces the need of blood transfusion in hip fracture surgery [11]. Moreover, TXA reduces blood loss during menstruation implicating that it has an effect on the fibrinolytic process in the uterus, which is important for women suffering from menorrhagia [12]. Von Holstein et al suggested in 1987 that TXA could be a favorable complement when treating bleeding conditions in the upper GI tract [13]. The use of TXA for upper GI bleeding has been debated. The medication was excluded from the Swedish state of the art recommendation, after the publication of a Meta-analysis from The Swedish Council on Health Technology Assessment 2011 (www.sbu.se) [14]. The authors indicated that there is not enough material to state its significance as inhibitor of fibrinolysis in the context of upper 


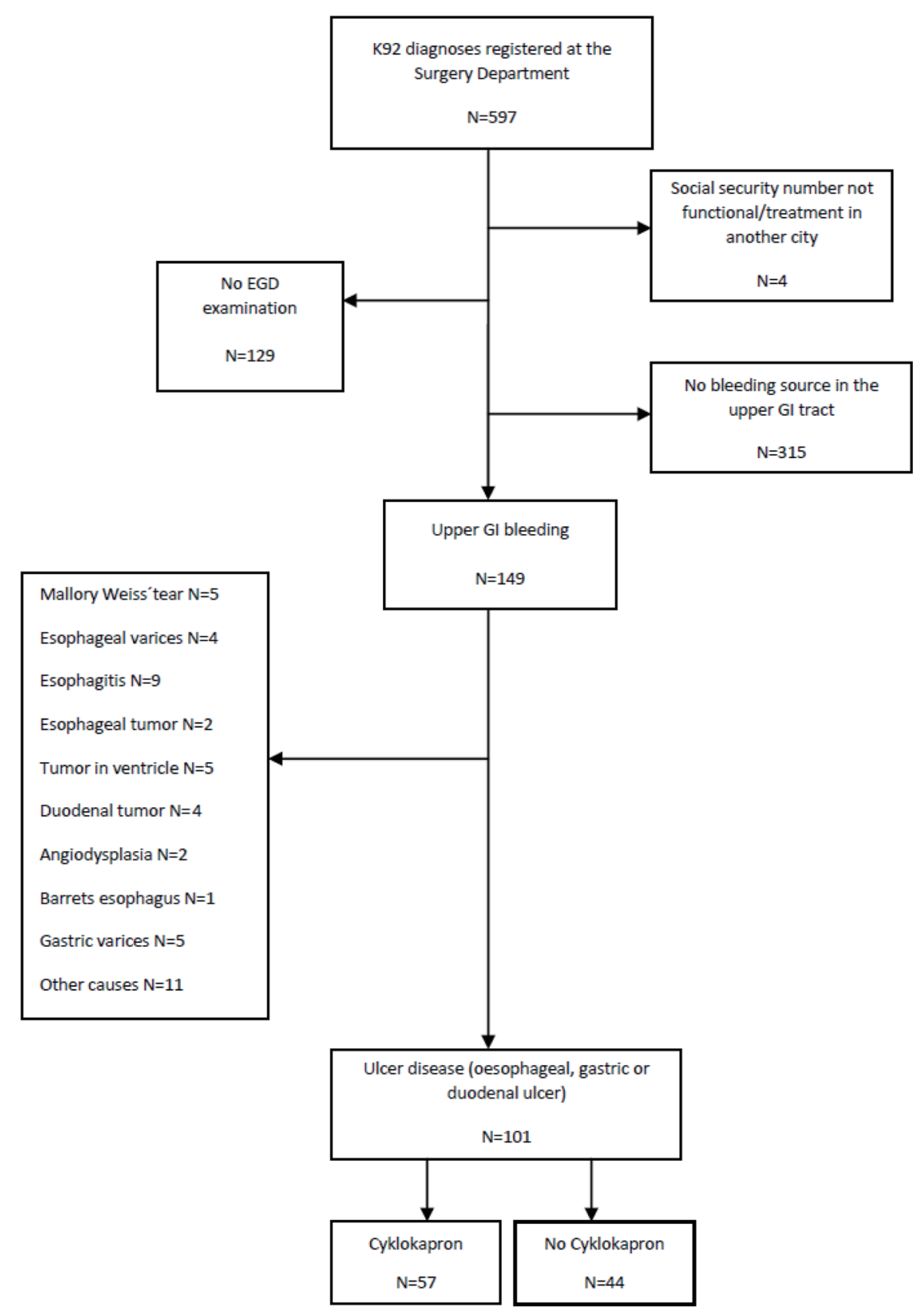

Figure 1. Flow chart for patient selection.

GI bleeding. The conclusion was based on a systematic review performed by Gluud et al, which included trials investigating the importance of TXA as a medical treatment to patients with upper GI bleeding [15]. In some trials, patients did not pass esophagogastroduodenoscopy (EGD) examination and the mean age in the trials was lower than what is generally considered for patients with upper GI bleeding [16].

The aim of this study was to compare results from patients treated for GI bleeding with and without TXA in a Swedish University Hospital after the publication of the Meta-analysis from The Swedish Council on Health Technology Assessment completed in 2011.

\section{Materials and Methods}

\section{Ethics}

This retrospective cohort study was performed during 2014 in accordance with the ethical declaration from the updated Helsinki Declaration. Information about each patient was 
Table 1. Gender and Age Division, Mean Value for Systolic Blood Pressure, Hemoglobin and Pulse Together With Cardinal Symptoms and Abdominal Pain in Total and for Each Group

\begin{tabular}{lllll}
\hline & Total $(\mathbf{N}=\mathbf{1 0 1})$ & TXA $(\mathbf{N}=\mathbf{5 7})$ & No TXA $(\mathbf{N}=\mathbf{4 4})$ & P value \\
\hline Women, N (\%) & $45(44.6)$ & $24(42.1)$ & $21(47.7)$ & 0.857 \\
Men, N (\%) & $56(55.4)$ & $33(59.9)$ & $23(52.3)$ & 0.866 \\
Mean age, years & 71 CI $(69-75)$ & 73 & 69 & 0.514 \\
Mean systolic blood pressure & 121 CI $(115-127)$ & 119 & 123 & 0.237 \\
Hemoglobin, mean value & 98 CI (92-103) & 93 & 102 & 0.177 \\
Pulse, mean value & 87 CI (84 - 92) & 84 & 90 & 0.211 \\
Hematemesis, N (\%) & $50(49.5)$ & $32(60.4)$ & $18(41.9)$ & 0.386 \\
Melena, N (\%) & $75(74.3)$ & $42(79.2)$ & $33(76.7)$ & 1.000 \\
Hematochezia, N (\%) & $11(12.1)$ & $7(14.3)$ & $4(9.5)$ & 0.755 \\
Abdominal pain or discomfort, N (\%) & $40(43.0)$ & $19(38.0)$ & $21(48.8)$ & 0.355 \\
\hline
\end{tabular}

collected from medical records at the University Hospital of Linkoping in Ostergotland, Sweden. The study was performed with approval from the local ethical committee.

\section{Study population}

Initially, the diagnoses of GI bleeding were gathered in form of diagnoses from International Statistical Classification of Diseases (ICD10). Hematemesis, melena and unspecified GI hemorrhage were the diagnoses in the study. At baseline, all patients diagnosed with melena, hematemesis and/or unspecified GI hemorrhage at the acute surgical ward between 2010 and 2013 were registered. A secretary using the ICD coding system in clinical routine performed this process to find the patients in the medical record system. Through this approach, patients with both upper and lower GI bleeding were identified. Inclusion criterion of this study was EGD-proven upper GI bleeding.

Through a review of the medical records $(\mathrm{N}=597)$, patients who had not been examined through EGD $(\mathrm{N}=129)$, patients with no bleeding source in the upper GI tract at EGD $(\mathrm{N}=315)$ and four with dysfunctional social security number not possible for examination were excluded, leaving 149. Among the remaining individuals $(\mathrm{N}=149)$, patients were grouped based on the cause of the bleeding. Mallory-Weiss tear $(\mathrm{N}=5)$, esophageal varices $(\mathrm{N}=4)$, esophagitis $(\mathrm{N}=9)$, esophageal tumor $(\mathrm{N}=2)$, tumor in ventricle $(\mathrm{N}=5)$, duodenal tumor $(\mathrm{N}=4)$, angiodysplasia $(\mathrm{N}=2)$, Barrets esophagus $(\mathrm{N}=1)$, gastric varices $(\mathrm{N}=$ $5)$, and other causes $(\mathrm{N}=11)$ were excluded. Patients with ulcer disease were finally included $(\mathrm{N}=101)$ (Fig. 1).

The records of the included individuals were examined in detail on the basis of the date of arrival to the Surgery Department. The numbers of individuals treated and not treated with TXA were registered.

\section{Study protocol}

Information about the patients was registered in a file based on a protocol including medical history, treatment and outcome.
The results from the review of the medical records were registered in the form of numbers corresponding to specific answers, 1 for yes and 0 for no. The medical history was primarily found in time of registration at the emergency or surgery unit and included: gender, age, hematemesis, melena, abdominal pain or discomfort, systolic blood pressure, pulse, hemoglobin $(\mathrm{Hb})$, and previous diseases organized into different categories (cancer disease, cardiovascular disease, lung disease, diseases related to the kidneys and urinary tract, blood disease, joint disease, diabetes, infectious disease and other diseases). Medical history also included present medication comprising a risk for ulcer disease, non-steroidal anti-inflammatory drugs (NSAIDs), acetylsalicylic acid (ASA), anticoagulant medication, and selective serotonin reuptake inhibitors (SSRIs) administered within 2 months before the bleeding episode. Medical treatment referred primarily to TXA medication of any kind, eradicative treatment (Nexium $\left.{ }^{\circledR} \mathrm{HP}\right)$ and PPIs during and/or after the medical care event (PPI IV or PO $20 \mathrm{mg} / 40$ $\mathrm{mg} \times 1$ or 2 ). EGD examination within $24 \mathrm{~h}$, adrenaline injection alone or in combination with other endoscopic treatments (thermal/mechanical methods) and surgery were registered. The primary outcome factors were: re-bleeding within 30 days, defined as signs of a new bleeding episode, for example increase of melena or a sudden decline in $\mathrm{Hb}$, re-gastroscopy, number of days hospitalized at the Surgery Department and/ or at the intensive care unit (ICU), death within 30 days after the medical care event (all-cause mortality) and the need of blood transfusion expressed as one or more microaggregate filter erythrocytes (MAF).

\section{Statistical analysis}

Patients treated with and without TXA formed two separate groups. Mean age and gender division were calculated for each group as well as mean value for blood pressure, $\mathrm{Hb}$ and pulse. Risk medication use was presented as median value.

Symptoms, previous/present diseases and outcomes were expressed as percent in each group. Median value was calculated for the number of days at the Surgery Department and/or 
Table 2. Medical History in Each Group Including Cardiovascular Disease and Median Value for Number of Used Risk Medication

\begin{tabular}{llll}
\hline & TXA & No TXA & P value \\
\hline Cardiovascular disease, N (\%) & $40(70.2)$ & $28(63.6)$ & 0.487 \\
Number of medications comprising a risk for ulcer disease Median value (min. - max.) & $1(0-4)$ & $1(0-3)$ & 0.732 \\
\hline
\end{tabular}

at the ICU. Differences between the groups were statistically examined through the Chi-squared test and the Mann-Whitney U test. All statistical calculations were performed in SPSS (Statistical Package for the Social Science) and P-value $<0.05$ was considered as statistically significant.

\section{Results}

Among the 597 medical care events where the ICD codes for melena, hematemesis and/or unspecified GI bleeding had been registered at the Surgery Department between 2010 and 2013, 101 admissions were registered as ulcer conditions. TXA was prescribed in $56 \%$ of the medical care events, whereas no TXA medication was prescribed in $44 \%$ of the cases. Sixty-five percent of the TXA medication was prescribed during 2010 and 2011 and 35\% was prescribed during 2012 and $2013(\mathrm{P}<0.05)$. Gender and mean age, together with medical condition and cardinal symptoms for the included patients, are presented in total and for the groups treated with and without TXA (Table 1).

In total, three patients had gastric bypass surgeries (treated like everyone else with ulcer in this study) and 14 had experienced previous ulcer disease. The majority of the patients (97\%) suffered/had suffered from one or several other diseases except from the present ulcer disease: cardiovascular disease $(\mathrm{N}=69)$, diabetes $(\mathrm{N}=23)$, cancer disease $(\mathrm{N}=18)$, disease in the kidneys or urinary tract $(\mathrm{N}=11)$, hematological disease $(\mathrm{N}$ $=8)$, joint disease $(\mathrm{N}=8)$, infectious disease $(\mathrm{N}=7)$, lung disease $(\mathrm{N}=6)$, parathyroid/thyroid disease $(\mathrm{N}=3)$ and other diseases $(\mathrm{N}=50)$. Results that concern medical history including previous and present cardiovascular disease and medication are also compiled for TXA group and non-TXA group (Table 2).

\section{Treatment}

In total $100 \%$ was treated with PPI, according to guidelines, during and/or after their hospitalization episode. During and/

Table 3. Treatment and EGD Within $24 \mathrm{~h}$ for Each Group Separately

\begin{tabular}{llll}
\hline & TXA & No TXA & P value \\
\hline PPI, N (\%) & $57(100)$ & $44(100)$ & x \\
Adrenaline, N (\%) & $20(36.4)$ & $8(18.6)$ & 0.053 \\
Other treatments, N (\%) & $16(28.1)$ & $5(11.9)$ & 0.052 \\
H. pylori eradication, N (\%) & $26(46.4)$ & $27(61.4)$ & 0.137 \\
EGD $<24$ h & $47(82.5)$ & $31(70.5)$ & 0.154 \\
\hline
\end{tabular}

$\mathrm{x}$ : no statistics because PPI was a constant. or after the patients' hospitalization episode, $100 \%$ was treated with PPI, all according to guidelines. A number of 28 received adrenaline injections during EGD, three went through surgical treatment (duodenotomy), 21 patients were treated with other methods, including thermal and mechanical methods, and 53 patients received a prescription of $H$. pylori eradicative treatment. The corresponding results for TXA group and non-TXA group are presented in Table 3 .

\section{Outcome}

Signs of re-bleeding were registered in 16 of the medical care events and 63 needed one or more MAF. Signs of re-bleeding were registered in 16 of the medical care events and 63 events needed one or more MAF. Medical care events at the Surgery Department solely occurred in 84 of the cases, whereas 17 occurred at the Surgery Department and at the ICU. The outcome results for each group are presented separately in Table 4. Gender and median age for each outcome are presented in Table 5. Three patients died within 30 days after admission.

\section{Discussion}

The aim of this study was to provide an overview of the trend in TXA prescription before and after the publication of the Meta-analysis from The Swedish Council on Health Technology Assessment in 2011, and to examine if treatment with TXA is favorable for patients with bleeding ulcer disease. Based on the present study it appears like TXA does not have a positive effect on patients with bleeding ulcers. A strength with this study is that all patients had passed EGD and were diagnosed with ulcer disease before they were included, which accordingly was a reassurance of the etiology of the bleeding. This made it clear that etiology and treatment were similar between the patients. The gender division, women $45 \%$ and men $55 \%$, respectively, was in accordance with previous incidence studies concluding that men suffer from ulcer disease more frequently than women [17]. The mean age was 69 in both groups, which reflects the generally accepted, high, mean age for bleeding ulcer patients.

The time when TXA was administered has not been taken into consideration since it, based on clinical praxis, is generally prescribed at the emergency department or when the patient arrives to the surgery department. An advantage with the exploration of TXA is that it is administered under controlled circumstances, so that compliance does not become a significant weakness in this study.

Only three of the included patients died within 30 days, 
Table 4. Outcome Factors for Each Group Including MAF, Re-Bleeding, Days at Hospital and Treatment at the Surgery Department and/or ICU

\begin{tabular}{llllll} 
& $\mathbf{>} \mathbf{0}$ MAF & Re-bleeding, N (\%) & $\begin{array}{l}\text { Days at hospital, median } \\
\text { value (min. - max.) }\end{array}$ & $\begin{array}{l}\text { Treatment at Surgery } \\
\text { Department, N (\%) }\end{array}$ & $\begin{array}{l}\text { Treatment at Surgery } \\
\text { Department and ICU, N (\%) }\end{array}$ \\
\hline TXA & $43(84.3)$ & $10(17.5)$ & $5(1-15)$ & $43(75.4)$ & $14(24.6)$ \\
No TXA & $20(64.5)$ & $6(13.6)$ & $3(0-39)$ & $41(93.2)$ & $3(6.8)$ \\
P-value & 0.039 & 0.594 & 0.005 & 0.018 & 0.018 \\
\hline
\end{tabular}

which is the reason that no statistical comparison could be performed between the groups with regard to this outcome. A slight difference was found between the two groups concerning re-bleeding, $(17.5 \%$ in the TXA group and $13.6 \%$ in the group not treated with TXA, Table 4). The result was not statistically significant, which can probably be explained as a consequence of the limited size of the patient group. Unlike the present study, von Holstein et al observed a lower frequency of re-bleeding in a group treated with TXA $(\mathrm{N}=10)$, compared to the placebo group $(\mathrm{N}=19)$. However, this result was neither statistically significant (0.097) [13].

Unexpectedly, the need of blood transfusion was greater among the patients who received TXA than among patients not treated with TXA, in the present study. The results seem contrary to previous studies that TXA in combination with acid reducing treatment will decrease the need of blood transfusion. Von Holstein et al noticed that the mean number of blood transfusions was only 4 units in the group treated with TXA, compared to 6 units in the placebo group $(\mathrm{P}=0.018)$ [13]. Furthermore, time hospitalized surprisingly appeared to be longer for patients in the TXA group compared to the control group, in the present trial. Table 2, however, presents a higher prevalence of cardiovascular diseases in the TXA group, which might be a significant confounding factor explicating the results. Moreover, patients in the TXA group needed adrenaline and other treatments more frequently than patients without TXA treatment $(\mathrm{P}=0.053$ and $\mathrm{P}=0.052)$. All together, these observations might be important since they signal that the patients in the TXA group were probably in a worse condition if compared to the patients that were not treated with TXA. The present results, which indicate that TXA is not beneficial for ulcer patients, might consequently, have been generated on the basis of a higher comorbidity in the TXA group. The mean age was 4 years higher in the group treated with TXA, which might also be an important factor explaining why the patients in the TXA group were in a worse condition. Rockall et al concluded that age and comorbidity are important factors determining the course of the bleeding ulcer disease [2].

This study shows that the main part, $65 \%$, of the TXA medication was prescribed during 2010 and 2011 compared to
$35 \%$ between 2012 and $2013(\mathrm{P}<0.05)$. This was in accordance with the initial hypothesis that most of the TXA prescription would occur during 2010 and 2011 (before the publication of the Meta-analysis from The Swedish Council on Health Technology Assessment in May 2011). It might take time for prescription recommendations to reach every clinician, which is why some prescription of TXA was expected after 2011. Nevertheless, the divergence in the prescription of TXA does signal that there might be a difference, not only based on clinical routines, but even differences between individual clinicians in their prescription habits. Variations in the severity of the patient's condition might influence if a clinician chooses to treat the patient with TXA or not. For this reason, an important confounding factor might be that patients in a more serious condition perhaps received the medication, while patients in a better condition did not receive TXA. Individual differences in prescription patterns among clinicians, based on variations in the patient conditions, are therefore a possible explanation to the current results. Based on this study, the prevailing theoretical insecurity about TXA and its significance for patients with bleeding ulcer disease appears to be reflected even in the clinic.

One of the patients was treated at the Surgery Department for bleeding ulcer but was afterwards treated for serious comorbidity at the ICU which is why many days at hospital were registered on this patient. Another patient re-emerged with upper GI bleeding but it was unclear if it was ulcers or varicose veins that had re-bled.

Experiments investigating how the acidic environment influences the effect of TXA are crucial knowledge important to emphasize. Patchett and O'Donoghue examined the effect of gastric juice, in combination with TXA and other medications, on coagulation and fibrinolysis through thrombelastography, and concluded that TXA might have a positive effect on fibrinolysis in the presence of gastric acid, but not on coagulation [18]. Von Holstein et al concluded in a double blind study that TXA could be effective for bleeding ulcer patients as a complement to acid reducing medication [13]. Medication reducing the acidic environment in the stomach might therefore be a prerequisite to receive a desirable effect of TXA. All

Table 5. Gender and Median Age for Outcome

\begin{tabular}{lllll}
\hline & MAF & Re-bleeding & $\begin{array}{l}\text { Treatment at the } \\
\text { Surgery Department }\end{array}$ & $\begin{array}{l}\text { Treatment at the } \\
\text { Surgery Department and ICU }\end{array}$ \\
\hline Men, N (\%) & $37(66.1)$ & $10(17.9)$ & $46(82.1)$ & $10(17.9)$ \\
Women, N (\%) & $26(57.8)$ & $6(13.3)$ & $38(84.4)$ & $7(15.6)$ \\
Age, median value (min. - max.) & $76(38-94)$ & $74(24-90)$ & $73(24-94)$ & $75(49-90)$ \\
\hline
\end{tabular}


patients received acid reducing medicine in the present study, which was an important observation due to its significance in ulcer treatment and the fact that it ascertained a similarity between the groups on this specific point.

The socioeconomic aspect is important to emphasize due to its essential role as a risk factor for ulcer disease. Staat et al claimed that the level of education is affecting the risk of getting infected and concluded that $H$. pylori is common in groups with low socioeconomic status [19]. Compliance, uppermost referring to administration of medication that will prevent new bleeding episodes, might also depend on the socioeconomic status. Our intention was to include smoking and alcohol habits in the calculation since they are both direct risk factors for upper GI bleeding, as well as they indirectly signal about socioeconomic conditions. Information about smoking and alcohol habits in medical records was, however, brief in general, which is why calculations on these factors were not completed.

In the clinic, the correct ICD code is not always connected to a specific condition, and the fact that information about patients is occasionally not registered in medical records, might be a problem from a research perspective. Ahsberg et al appointed that misclassification of ulcer conditions is common [7].

When a patient with hematemesis and melena at the Emergency Department is further examined through EGD at the surgical ward, the ICD codes for these conditions (K92) are registered at the Surgery Department if the bleeding is not very prominent, as a sign that a bleeding session however has occurred. The ICD codes for hematemesis and melena might therefore not be registered in terms of all bleeding condition at the Surgery Department, since the ICD codes K25, K26 and K28 are used instead. For this reason, investigation including an expanded study population is required to cover even this group of bleeding patients.

A considerable group of individuals is necessary to achieve statistic power and clarify the significance of TXA in the context of bleeding ulcers. Further studies are required to explain the role of TXA in bleeding ulcer conditions, since the medication is proven to be effective for bleeding episodes in other parts of the body, as well as it has been suggested to have a positive effect even in the acidic GI system. The risk of thromboembolism after treatment with TXA, which has been examined in some studies, was not investigated in the present study and requires to be further evaluated if new TXA recommendations will be made [20]. As suggested by the recent review that TXA appears to have beneficial effect on mortality, there is need for further studies [21].

\section{Conclusion}

The prescription of TXA has declined after the publication of the Meta-analysis from The Swedish Council on Health Technology Assessment. Variations in the prescription habits, however, indicate that there is a prevailing insecurity among the clinicians concerning TXA and when it is supposed to be prescribed to generate the best, possible result for patients with bleeding ulcers. The present study could not manifest a positive effect of TXA on patients with bleeding ulcer disease, which was probably a consequence of a higher comorbidity in the group treated with TXA. Further investigation, including an expanded group of ulcer patients, is necessary to be able to confirm the role of TXA in bleeding ulcer conditions.

\section{Conflicts of Interest}

None.

\section{Grant/Financial Support}

None.

\section{Sources of Funding}

None.

\section{References}

1. Ahsberg K, Ye W, Lu Y, Zheng Z, Stael von Holstein C. Hospitalisation of and mortality from bleeding peptic ulcer in Sweden: a nationwide time-trend analysis. Aliment Pharmacol Ther. 2011;33(5):578-584.

2. Rockall TA, Logan RF, Devlin HB, Northfield TC. Incidence of and mortality from acute upper gastrointestinal haemorrhage in the United Kingdom. Steering Committee and members of the National Audit of Acute Upper Gastrointestinal Haemorrhage. BMJ. 1995;311(6999):222226.

3. Wara P, Stodkilde H. Bleeding pattern before admission as guideline for emergency endoscopy. Scand J Gastroenterol. 1985;20(1):72-78.

4. Katschinski BD, Logan RF. Changes in birth-cohort pattern of peptic ulcer mortality in England and Wales. Postgrad Med J. 1991;67(791):825-828.

5. Chung SS, Lau JY, Sung JJ, Chan AC, Lai CW, Ng EK, Chan FK, et al. Randomised comparison between adrenaline injection alone and adrenaline injection plus heat probe treatment for actively bleeding ulcers. BMJ. 1997;314(7090):1307-1311.

6. Hermansson M, Ekedahl A, Ranstam J, Zilling T. Decreasing incidence of peptic ulcer complications after the introduction of the proton pump inhibitors, a study of the Swedish population from 1974-2002. BMC Gastroenterol. 2009;9:25.

7. Ahsberg K, Hoglund P, Stael von Holstein C. Mortality from peptic ulcer bleeding: the impact of comorbidity and the use of drugs that promote bleeding. Aliment Pharmacol Ther. 2010;32(6):801-810.

8. Hoylaerts M, Lijnen HR, Collen D. Studies on the mechanism of the antifibrinolytic action of tranexamic acid. Biochim Biophys Acta. 1981;673(1):75-85.

9. Shakur H, Roberts I, Bautista R, Caballero J, Coats T, Dewan Y, El-Sayed H, et al. Effects of tranexamic acid 
on death, vascular occlusive events, and blood transfusion in trauma patients with significant haemorrhage (CRASH-2): a randomised, placebo-controlled trial. Lancet. 2010;376(9734):23-32.

10. Crescenti A, Borghi G, Bignami E, Bertarelli G, Landoni G, Casiraghi GM, Briganti A, et al. Intraoperative use of tranexamic acid to reduce transfusion rate in patients undergoing radical retropubic prostatectomy: double blind, randomised, placebo controlled trial. BMJ. 2011;343:d5701.

11. Zufferey PJ, Miquet M, Quenet S, Martin P, Adam P, Albaladejo P, Mismetti $\mathrm{P}$, et al. Tranexamic acid in hip fracture surgery: a randomized controlled trial. Br J Anaesth. 2010;104(1):23-30.

12. Lukes AS, Moore KA, Muse KN, Gersten JK, Hecht BR, Edlund M, Richter HE, et al. Tranexamic acid treatment for heavy menstrual bleeding: a randomized controlled trial. Obstet Gynecol. 2010;116(4):865-875.

13. von Holstein CC, Eriksson SB, Kallen R. Tranexamic acid in gastric and duodenal bleeding. Scand J Gastroenterol Suppl. 1987;137:71-74.

14. SBU. Blodande magsar. En systematisk litteraturoversikt. Stockholm: Statens beredning for medicinsk utvardering (SBU); 2011. SBU-rapport nr 206. ISBN 978-91-8541342-3.
15. Gluud LL, Klingenberg SL, Langholz SE. Systematic review: tranexamic acid for upper gastrointestinal bleeding. Aliment Pharmacol Ther. 2008;27(9):752-758.

16. Hawkey GM, Cole AT, McIntyre AS, Long RG, Hawkey CJ. Drug treatments in upper gastrointestinal bleeding: value of endoscopic findings as surrogate end points. Gut. 2001;49(3):372-379.

17. Lindell G, Celebioglu F, Von Holstein CS, Graffner H. On the natural history of peptic ulcer. Scand J Gastroenterol. 1994;29(11):979-982.

18. Patchett SE, O'Donoghue DP. Pharmacological manipulation of gastric juice: thrombelastographic assessment and implications for treatment of gastrointestinal haemorrhage. Gut. 1995;36(3):358-362.

19. Staat MA, Kruszon-Moran D, McQuillan GM, Kaslow RA. A population-based serologic survey of Helicobacter pylori infection in children and adolescents in the United States. J Infect Dis. 1996;174(5):1120-1123.

20. Sadic J, Borgstrom A, Manjer J, Toth E, Lindell G. Bleeding peptic ulcer - time trends in incidence, treatment and mortality in Sweden. Aliment Pharmacol Ther. 2009;30(4):392-398.

21. Bennett C, Klingenberg SL, Langholz E, Gluud LL. Tranexamic acid for upper gastrointestinal bleeding. Cochrane Database Syst Rev. 2014;(11):CD006640. 